\title{
- PROCESSO DE RECRUTAMENTO E SELEÇÃo EM UMA COOPERATIVA DE CRÉDITO
}

\section{ESTUDO DE CASO}

FERREIRA, Ana Clara Resende ${ }^{1}$

CARLOS, Greiciani Assunção ${ }^{2}$

GONÇALVES, Marise de Oliveira ${ }^{3}$

MOREIRA, Andréia Aparecida Silva ${ }^{4}$

FERREIRA, Ana Clara Resende. Et al. O processo de recrutamento e seleção em uma cooperativa de crédito. Revista Científica Multidisciplinar Núcleo do Conhecimento. Ano 03, Ed. 09, Vol. 09, pp. 165-180 Setembro de 2018. ISSN:24480959

\section{RESUMO}

O processo de Recrutamento e Seleção foi escolhido neste trabalho por ser o primeiro passo da empresa na área de Gestão de Recursos Humanos, visando contratar o perfil mais adequado para o profissional que está buscando. Este trabalho tem o objetivo não só de entender como é realizado o recrutamento e seleção da Cooperativa, mas também expressar a teoria deste processo e o que está acontecendo na prática da organização. $O$ estudo sobre o processo de recrutamento e seleção em uma cooperativa de crédito será de extrema importância, visto que, a cobrança por melhores resultados, por um atendimento ao cliente qualificado e por

\footnotetext{
${ }^{1}$ Graduanda em Administração na Universidade do Estado de Minas Gerais (Uemg).

${ }^{2}$ Graduanda em Administração na Universidade do Estado de Minas Gerais (Uemg).

${ }^{3}$ Graduanda em Administração na Universidade do Estado de Minas Gerais (Uemg).

${ }^{4}$ Professora na Universidade do Estado de Minas Gerais (Uemg).
} 
inovações surpreendentes está aumentando a cada dia que passa. O procedimento metodológico para coleta e operacionalização das informações dessa pesquisa se caracteriza como descritiva, bibliográfica; quantos aos meios se classifica como um estudo de caso, com abordagem qualitativa e quantitativa. Essa análise teve como base análise documentos do departamento pessoal e do setor de recursos humanos, observações do ambiente de trabalho e entrevistas semiestruturadas; o universo da pesquisa foi uma Cooperativa de Crédito, onde a amostra intencional foi representada pelo Diretor Coordenador Administrativo, a Analista de Recursos Humanos e a Auxiliar de Departamento Pessoal. Os resultados obtidos indicam que apesar de utilizar técnicas eficazes, o processo de recrutamento e seleção da Cooperativa necessita de aperfeiçoamento.

Palavras-chaves: Recrutamento, Seleção, Cooperativa, Profissionais.

\section{INTRODUÇÃO}

O processo de Recrutamento e Seleção de pessoas é um método utilizado para incorporar novos talentos as organizações. Segundo Chiavenato (2002), recrutamento são métodos e processos que buscam atrair candidatos competentes e capacitados para ocupar cargos dentro da organização por onde a empresa oferece ao mercado de recursos humanos vagas de emprego que pretende preencher.

A fase de seleção, de acordo com Caxito (2008), é designar o melhor candidato para a vaga. É através da seleção que a empresa escolhe, dentre os recrutados, o candidato que atingir melhor os padrões de seleção para o cargo.

Este trabalho foi realizado em uma Cooperativa de Crédito com o objetivo de analisar se o processo de recrutamento e seleção está estruturado e se está trazendo resultados positivos para a organização.

A Cooperativa de Crédito convergiu esforços dos empresários locais que iniciaram o trabalho de viabilização e constituição em 19/09/1997. Tiveram início em 13/07/1998. Desde maio de 2010, a Cooperativa foi autorizada pelo Banco Central e tornou-se de 
livre admissão, possibilitando o acesso de todas as pessoas físicas e jurídicas aos serviços da instituição. Exerce sua função através da Assembleia Geral, órgão supremo da cooperativa do Conselho de Administração, Diretoria Executiva e Conselho Fiscal. Possui um quadro de 104 funcionários, 8 estagiários e 4 menores aprendizes, que trabalham em função de seus 12.672 associados.

De acordo com o exposto no parágrafo anterior tem-se o seguinte problema: As técnicas utilizadas no processo de recrutamento e seleção da cooperativa são eficazes ou é preciso uma reestruturação?

Para responder o problema em questão, foram estabelecidas algumas hipóteses, que guiarão o estudo:

1. Acredita-se que o processo de recrutamento e seleção pode conter falhas, contratando pessoas que não tenham perfil para o cargo.

2. As ferramentas de avaliação podem conter falhas devido ao não profissionalismo da diretoria, solicitando que o setor de Recursos Humanos coloque pessoas indicadas por eles.

3. Os custos com o processo seletivo são baixos, uma vez que é realizado primeiro o recrutamento interno para depois buscar profissionais no mercado.

O objetivo geral deste artigo é analisar se o processo de recrutamento e seleção da cooperativa está estruturado e trazendo resultados positivos. Os específicos são: a) Estudar os fundamentos teóricos sobre recrutamento e seleção e associá-los a realidade da empresa em estudo; b) Conhecer o conjunto de fatores que caracterizam o processo de recrutamento e seleção da cooperativa; c) Descrever como é realizado o recrutamento e seleção da cooperativa.

A execução deste artigo se justifica por ser uma oportunidade de relacionar a teoria estudada no curso de administração em especial na matéria de gestão de pessoas 
com a prática vivenciada na cooperativa. Além de sugerir melhorias para os processos de recrutamento e seleção.

Para melhor entendimento deste trabalho o texto está estruturado em seção 1: introdução; seção 2: fundamentação teórica; seção 3: metodologia; seção 4: análise e interpretação dos dados; seção 5: fizeram-se as considerações finais e por fim as referências que serão citadas ao longo deste trabalho.

\section{REFERENCIAL TEÓRICO}

Chiavenato (2002) oferece uma importante contribuição em dizer que recrutamento são métodos e processos que buscam atrair candidatos competentes e capacitados para ocupar cargos dentro da organização por onde a empresa oferece ao mercado de recursos humanos vagas de emprego que pretende preencher.

De acordo com Chiavenato (2002), recrutamento interno é quando surge uma vaga dentro da organização e a empresa busca preenchê-la através da mudança de seus funcionários, que podem ser promovidos de cargos ou apenas transferidos.

Ainda segundo Chiavenato (2002), o recrutamento interno é mais econômico, pois não necessita de despesas com anúncios em jornais e revistas, não tem custos de admissão e nem com integração do novo funcionário; é mais rápido, pois evita as demoras do recrutamento externo, é uma fonte de motivação para os colaboradores trazendo possibilidades de crescimento dentro da empresa visando uma futura promoção e é uma forma mais segura devido o candidato já ser conhecido.

Para Caxito (2008), no processo de recrutamento interno, as vagas são ocupadas através da seleção de colaboradores que já trabalham na organização. Esse processo motiva o crescimento profissional do funcionário ajudando na fidelidade à organização. Contudo é uma forma de impedir a entrada de novas ideias e experiências na empresa. 
O recrutamento externo, de acordo com Chiavenato (2002), acontece com candidatos que ainda não trabalham na empresa. Quando aparece uma vaga, a empresa busca preenchê-la com candidatos externos.

Para Caxito (2008), selecionar é designar o melhor candidato para a vaga. É através da seleção que a empresa escolhe, dentre os recrutados, o candidato que atingir melhor os padrões de seleção para o cargo.

[...] a seleção busca entre os candidatos recrutados aqueles mais adequados aos cargos existentes na empresa, visando a manter ou aumentar a eficiência e o desempenho do pessoal, bem como a eficácia da organização (CHIAVENATO, 2002, p. 223).

Segundo Caxito (2008), o processo de seleção de pessoas passa por várias etapas e cada uma delas devem estar interligadas. A primeira é a atração, onde o profissional de $\mathrm{RH}$ precisa atrair o candidato. A segunda é a triagem voltada para a eliminação dos candidatos que não são qualificados. A avaliação é a terceira, onde os selecionadores utilizam as técnicas de seleção para avaliar os candidatos préselecionados. Por fim, a quarta etapa é a da decisão, onde as ações desenvolvidas pelos selecionadores ajudam a decidir quais serão os candidatos finais.

De acordo com Caxito (2008), a técnica mais utilizada para os processos seletivos é a entrevista. É muito utilizada devido ao baixo custo, a facilidade de aplicar, a quantidade de sensações, impressões e informações que o selecionador pode obter do candidato. Além disso, a entrevista possibilita um contato direto com o candidato, podendo tirar possíveis dúvidas e também clarear alguns pontos. Ainda segundo o autor, há vários tipos de entrevistas como a não-estruturada, a planejada, a comportamental e a situacional ou de simulação.

O teste psicológico, segundo Limongi-França e Arellano (2002), é um conjunto de provas que se aplica para poder avaliar como é o desenvolvimento mental das pessoas, assim como suas habilidades, suas aptidões e seus conhecimentos. 
Os testes psicológicos constituem uma medida objetiva e estandardizada de uma amostra do comportamento no que se refere a aptidões das pessoas. Os testes psicológicos são utilizados como uma medida de desempenho e se baseiam em amostras estatísticas de comparação, sendo aplicados sob condições padronizadas. Os resultados dos testes de uma pessoa são comparados com padrões de resultado em amostras representativas para obter resultados em percentis (CHIAVENATO, 2010, p. 151).

Os custos com recrutamento são acarretados por anúncios da disponibilidade da vaga na mídia e agências de emprego. Logo após, acontecem as entrevistas, testes psicológicos e exame admissional. Depois, ao ser selecionado, o funcionário é submetido a treinamento que também ocasiona perdas de produtividade. De acordo Silva (2007) apud Lopes de Sá e Padroni (1984), para que se consiga controlar o pessoal é fundamental que haja um departamento específico que acompanhe o colaborador desde sua admissão, desenvolvimento e demissão.

Em quase todos os casos a fórmula padrão aplicada ao custo de admissão é: publicação de anúncios, gastos com agências de recrutamento e seleção e serviços de terceiros, locação de espaços externos, testes psicológicos, exames médicos, pagamento de luvas, viagem e hospedagem de candidatos, custo com a equipe, desde salários e encargos, até viagens, e quaisquer outras despesas relacionadas a admissão. Mais importante do que determinar os custos gerais de contratação de pessoal, é a determinação de onde esse gasto está sendo aplicado e como poderá ser reduzido (SILVA, 2007, p. 5).

\section{METODOLOGIA}

Visando responder ao problema se as técnicas utilizadas no processo de recrutamento e seleção da cooperativa são eficazes ou se é preciso uma reestruturação foi desenvolvida uma pesquisa, cuja abordagem caracterizou-se como 
qualitativa. Pois segundo Gil (2002), buscou descrever significados que são considerados como inerentes aos objetos e atos, por isso é definida como objetiva.

Teve como característica permitir uma abordagem focalizada, pontual e estruturada, utilizando-se de dados quantitativos. A coleta de dados quantitativos realizou-se através da obtenção de respostas estruturadas. Para atingir os objetivos propostos, o que se pretendeu foi analisar as informações obtidas nos documentos, livros e dissertações disponíveis na internet.

Quanto aos fins, a pesquisa caracterizou-se como descritiva, uma vez que, os dados coletados permitiram descrever se as técnicas utilizadas no processo de recrutamento e seleção da cooperativa são eficazes ou se é preciso uma reestruturação.

A pesquisa descritiva, segundo Oliveira (2001, p. 114) "possibilita o desenvolvimento de um nível de análise em que se permite identificar as diferentes formas dos fenômenos, sua ordenação e classificação".

Tal estudo favorece a explicação das relações de causa e efeito, podendo, assim, analisar as variáveis que influenciam no aparecimento desses fenômenos. Devido ao objetivo de se compreender de uma forma mais apurada os elementos que influenciam a cultura da empresa, acredita-se que a pesquisa descritiva seja mais indicada. (OLIVEIRA, 2001, p. 114).

Quanto aos meios, a pesquisa caracteriza-se como um estudo de caso, considerado o melhor caminho para o alcance do objetivo principal deste estudo, de analisar se o processo de recrutamento e seleção da cooperativa está estruturado e trazendo resultados positivos.

Através do estudo de caso, pôde-se realizar uma investigação intensiva de um dado fenômeno, obtendo informações aprofundadas, que possibilitam uma maior compreensão da realidade pesquisada. 
O universo estudado foi uma Cooperativa de Crédito. A amostra representada pelo Diretor Coordenador Administrativo, o responsável pelo $\mathrm{RH}$ e departamento de pessoal. Os instrumentos utilizados para a coleta de dados foram documentos, observações e entrevistas semiestruturadas.

Foi feita uma observação sistemática do ambiente de trabalho que Segundo Lakatos e Marconi (2001), a observação é uma forma de se obterem dados de determinados aspectos da realidade, utilizando-se os sentidos.

Finalmente realizou-se a tabulação e análise dos dados de forma a atender os objetivos deste trabalho.

\section{ANÁLISE E TABULAÇÃO DE DADOS}

Várias questões sobre o processo de recrutamento e seleção da cooperativa foram coletadas, através de entrevistas com o Diretor Coordenador Administrativo, a Analista de Recursos Humanos e a Auxiliar de Departamento Pessoal. A entrevista foi realizada com as três pessoas ao mesmo tempo, por isso não há um discurso de cada representante da equipe de recursos humanos. Optou-se por fazer a entrevista com os três simultaneamente porque eles são muito unidos, fazem tudo junto e além disso, são abertos a críticas construtivas e sugestões de melhoria.

De acordo com o primeiro gráfico, $17 \%$ dos entrevistados são do sexo masculino enquanto $83 \%$ são do sexo feminino. 
Gráfico 1: Sexo

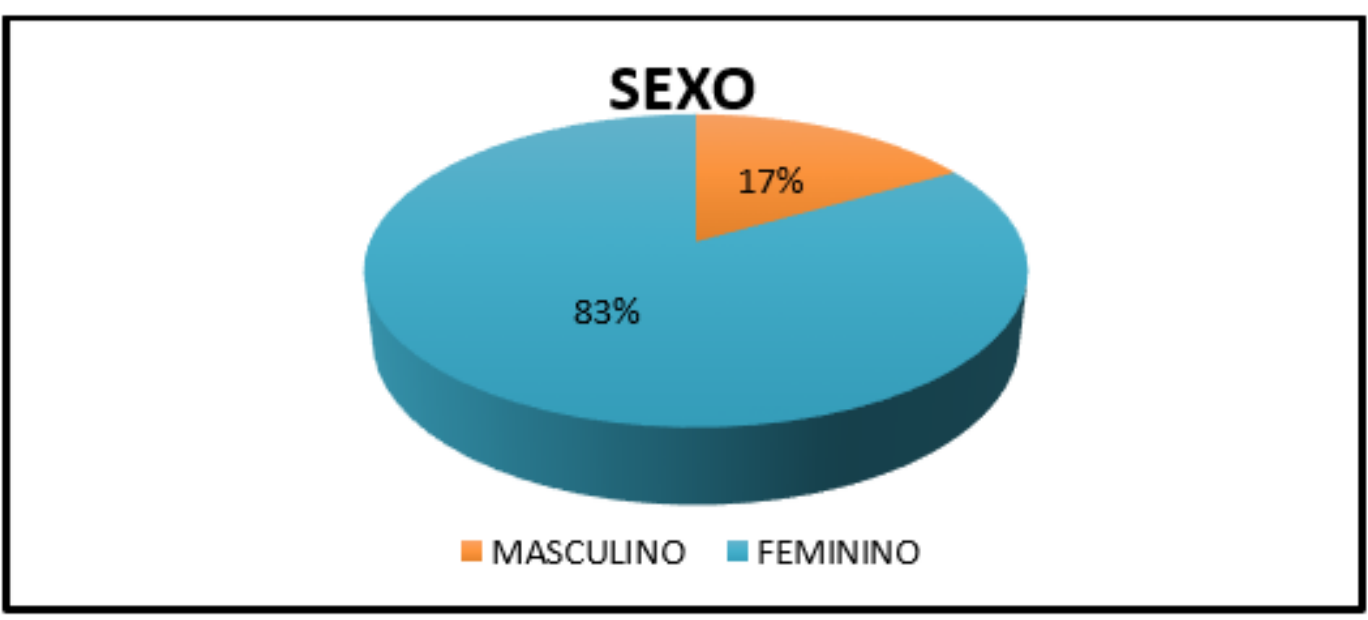

Fonte: Dados da pesquisa 2017

Observando o gráfico 2, percebe-se que $50 \%$ dos entrevistados possuem de 24 a 28 anos, $33 \%$ de 29 a 33 anos e $17 \%$ de 39 a 48 anos.

Gráfico 2: Faixa etária

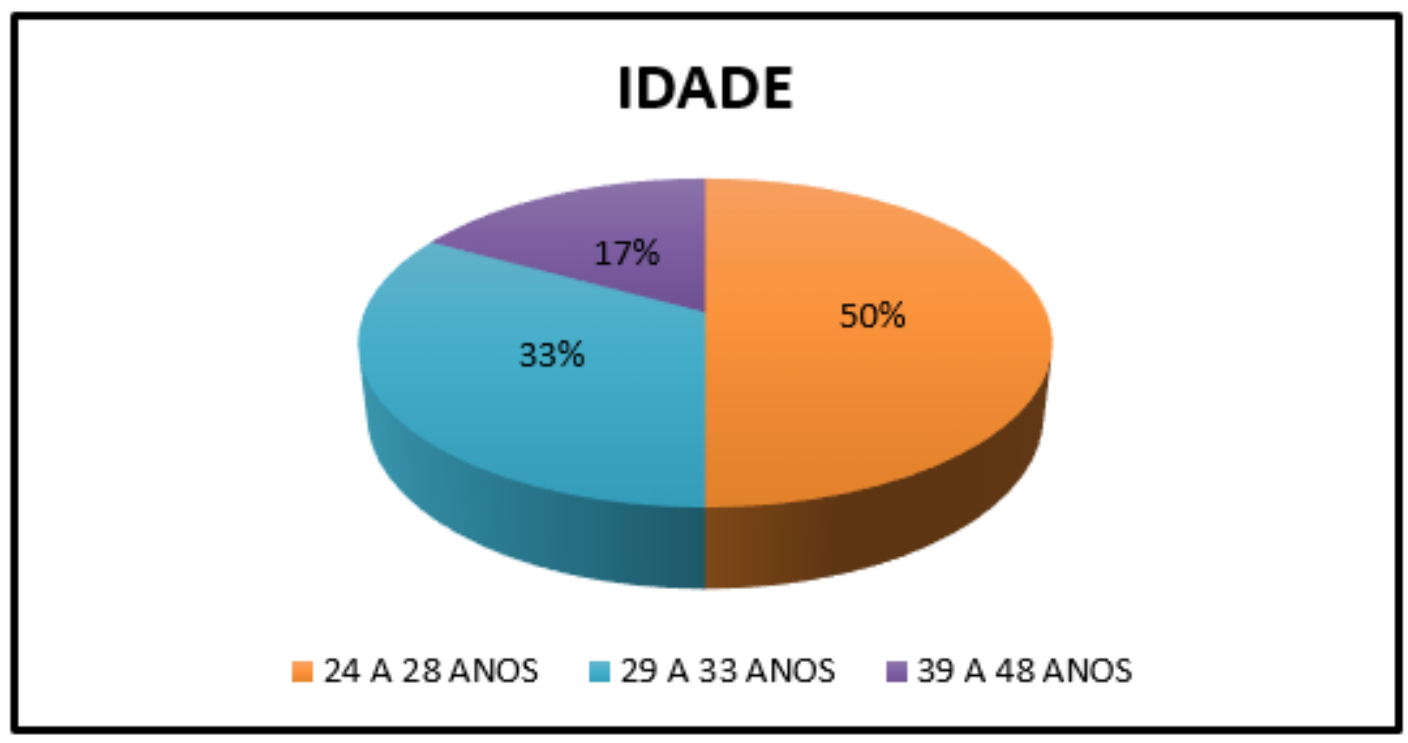

Fonte: Dados da Pesquisa 2017

RC: 20727

Disponível em: https://www.nucleodoconhecimento.com.br/administracao/processo-derecrutamento 
Segundo o gráfico 3, nota-se que $67 \%$ das pessoas entrevistadas já fizeram pósgraduação e $33 \%$ fizeram mestrado.

Gráfico 3: Grau de escolaridade

\section{GRAU DE ESCOLARIDADE}

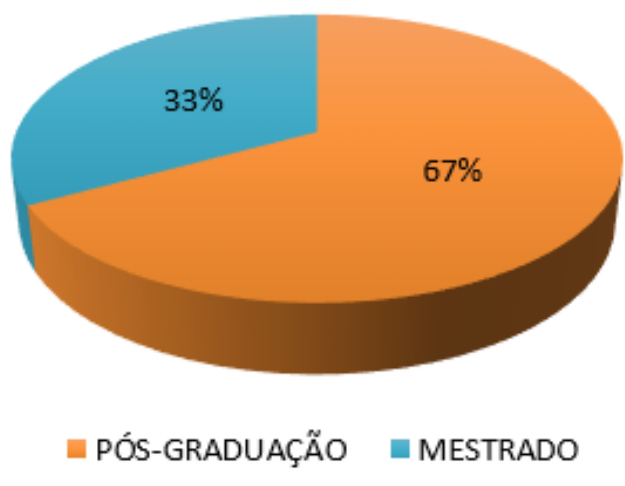

Fonte: Dados da pesquisa 2017

Conforme o quarto gráfico, $17 \%$ dos entrevistados trabalham na cooperativa entre 1 a cinco anos e $83 \%$ trabalham de 5 a 10 anos.

Gráfico 4: Tempo de serviço

\section{TEMPO DE SERVIÇO NA EMPRESA}

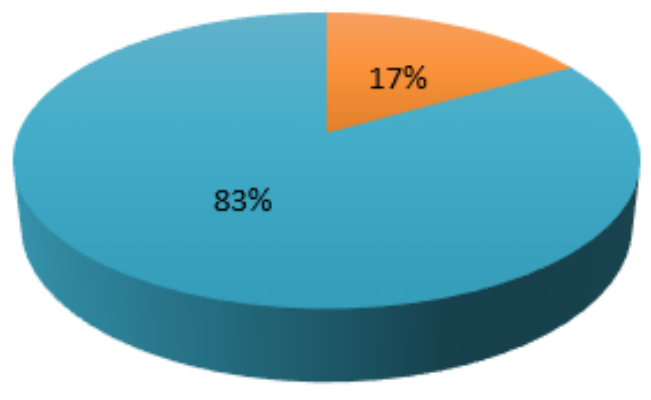

ENTRE 1 E 5 ANOS ENTRE 5 E 10 ANOS

Fonte: Dados da pesquisa 2017

RC: 20727

Disponível em: https://www.nucleodoconhecimento.com.br/administracao/processo-derecrutamento 
Quando foi perguntado para a diretoria, recursos humanos e departamento pessoal da empresa como é a rotatividade de funcionários eles disseram que está em média de $3 \%$ para a cooperativa no geral, lembrando que esta rotatividade está somente na entrada de funcionários. Funcionários demitidos ou que pediram demissão está controlado. Mas a constante contratação de funcionários é devido à abertura de novas agências e crescimento da organização.

De acordo com a pergunta 2, se o processo de recrutamento e seleção é eficaz, o RH respondeu que sim, porém a diretoria ressaltou que algumas vezes há falhas na seleção, contratando profissionais que não tem a qualificação para o cargo, ou que não tem perfil, não há um profissionalismo ao fazer a avaliação desses funcionários recrutados.

Segundo a pergunta 3, como é feito o processo de recrutamento e seleção e quais são as técnicas utilizadas, foi descrito que o recrutamento é feito da seguinte forma: primeiramente é feita uma divulgação do concurso nas rádios, escolas e faculdades através de cartazes. Os candidatos preenchem um formulário de inscrição nas agências e depois fazem uma avaliação de português e matemática. Os primeiros classificados são chamados para uma entrevista e para um teste de digitação. Após essa entrevista é feito um banco de talentos onde os candidatos são chamados à medida que a empresa vai precisando. O resultado segue os padrões relatados por Chiavenato (2002) que diz que em um processo seletivo deve-se primeiro lançar as vagas no mercado pelo máximo de meios de comunicação possível e depois de selecionados, os candidatos devem passar por testes e entrevistas formando um banco de talentos para a organização.

Perguntou-se quais são os critérios utilizados para o processo de recrutamento e seleção, utiliza-se de provas de conhecimentos, testes de informática e entrevista comportamental.

Conforme a pergunta que diz se é feito um planejamento de recrutamento e seleção, apesar de utilizar técnicas eficazes não há um planejamento específico e muitas vezes 
há falhas nos processos seletivos, pois algumas entrevistas não são feitas com profissionalismo, classificando pessoas a pedido da diretoria.

Quando foi perguntado se é feito uma avaliação do recrutamento e seleção eles disseram que não, talvez por não conhecerem as ferramentas de avaliação.

Questionados sobre qual o absenteísmo, segundo os entrevistados o absenteísmo da cooperativa é baixo. O percentual mensal varia de $1 \%$ a $2 \%$ e o anual $1,5 \%$. Não há funcionários afastados pelo INSS ou com doença do trabalho.

Quando foram perguntados sobre quais são os motivos para demitir um funcionário e quais são os motivos dos funcionários pedirem demissão, foi relatado que as demissões são devido à inadequação ao cargo e ou atividades realizadas ou então ao descumprimento de algumas normas internas. Já os pedidos de demissão são devido a novas propostas profissionais ou então a mudança de cidade.

Perguntou-se também como é feita a entrevista de desligamento, foi dito que há um questionário que é aplicado ao funcionário desligado após a assinatura dos documentos da rescisão e posteriormente encaminhado à diretoria para análise.

Quando interrogados sobre quais são os custos dos processos seletivos, disseram que é baixo, pois primeiro é feito o recrutamento interno aproveitando os talentos da cooperativa para depois anunciar as vagas no mercado. $O$ anuncio é feito através de rádio e panfletos e quem faz os processos são a equipe de Recursos Humanos juntamente com o Diretor Coordenador Administrativo. Após a admissão ou promoção do colaborador o mesmo é acompanhado, treinado e avaliado, evitando assim rotatividade e custos por erros no processo seletivo, apesar de algumas vezes contratar pessoas que não tem perfil para o cargo. A resposta está de acordo com que diz Silva (2007), que relata que os custos com processo seletivo estão relacionados ao anúncio de vagas, testes aplicados e exames admissionais, além dos treinamentos, salários e benefícios. E que sempre que possível fazer o recrutamento interno, pois os custos são menores. 
Por fim, a última pergunta fala sobre os pontos fortes e fracos do processo de recrutamento e seleção da cooperativa. Foi descrito da seguinte forma:

- Pontos fortes do recrutamento interno - econômico, rápido, seguro; motiva o desenvolvimento de todos; motiva a permanência e lealdade na empresa e gera uma competição sadia entre os funcionários.

- Pontos fracos do recrutamento interno - pode gerar frustração nos funcionários que não forem aprovados; pode desmotivar e gerar conflitos internos.

- Pontos fortes do recrutamento externo - novas ideias para a empresa; novos talentos; enriquece o patrimônio humano; enriquece o capital intelectual da empresa.

- Pontos fracos do recrutamento externo - é mais caro, demorado e menos seguro; desmotiva os funcionários da empresa que esperam por uma oportunidade.

Conclui-se que o recrutamento e seleção da cooperativa de crédito possui técnicas eficazes, porém alguns processos precisam ser reestruturados. Criar o planejamento do recrutamento e seleção, atuar com profissionalismo, avaliar os processos seletivos, sanar as falhas contratando profissionais com perfil para a vaga e aplicar testes psicológicos.

\section{CONCLUSÃO}

O objetivo deste trabalho foi analisar, diante de um conjunto de fatores estudados, se as técnicas utilizadas no processo de recrutamento e seleção de uma Cooperativa de Crédito são eficazes ou se é preciso uma reestruturação.

O problema "As técnicas utilizadas no processo de recrutamento e seleção da cooperativa são eficazes ou é preciso uma reestruturação" foi respondido. As técnicas são eficazes, porém possuem algumas falhas que precisam ser reestruturadas. Não há um planejamento do recrutamento e seleção, falta profissionalismo, classificando pessoas a pedido da diretoria e não há uma avaliação do recrutamento e seleção. 
Verificou-se também que as hipóteses são verdadeiras, pois algumas vezes o recrutador da cooperativa contrata pessoas que não tem perfil para o cargo, a diretoria pede que seja contratado alguns profissionais sem processo seletivo e os custos com o recrutamento e seleção são baixos.

O objetivo geral "Analisar se o processo de recrutamento e seleção da cooperativa está estruturado e trazendo resultados positivos" pôde ser alcançado através da análise e tabulação de dados, onde podemos perceber que, apesar do grande desenvolvimento da cooperativa, existem algumas falhas no processo de recrutamento e seleção. Embora sejam utilizadas técnicas eficazes, não há um planejamento específico, existem profissionais contratados que não possuem a qualificação necessária para o cargo e também alguns que são contratados a pedido da diretoria.

Após a análise da entrevista, estudo do referencial teórico e observação do ambiente de trabalho percebe-se que no geral o recrutamento e seleção da cooperativa precisa ser melhorado, pois apresenta algumas falhas. Desta forma, sugere-se o seguinte plano de ação:

- Atuar com profissionalismo;

- Utilizar mais ferramentas comportamentais, como testes psicológicos;

- Fazer um planejamento de recrutamento e seleção bem elaborado e estruturado.

- Avaliar o recrutamento e seleção, corrigindo as falhas.

Adotando essas medidas a Cooperativa de Crédito poderá alcançar melhores resultados no processo de recrutamento e seleção.

\section{REFERÊNCIAS}

CAXITO, Fabiano de Andrade. Recrutamento e Seleção de Pessoas. IESDE Brasil S.A., 2008. 
CHIAVENATO, Idalberto. Gestão de Pessoas, Terceira Edição Totalmente Revista e Atualizada. 6- Tiragem. Elsevier Editora Ltda, 2010.

Recursos Humanos Edição Compacta, $7^{a}$ edição. São Paulo: Editora Atlas S.A. 2002.

GIL, Antônio Carlos. Como elaborar projetos de pesquisa. 4. ed. São Paulo: Atlas, 2002

LAKATOS, Eva Maria; MARCONI, Marina de Andrade. Fundamentos de metodologia científica. 4. ed. rev. e ampl. 6. tir. São Paulo: Atlas, 2001.

LAKATOS, Eva Maria; MARCONI, Marina de Andrade. A.;. Metodologia do trabalho científico: procedimentos básicos, pesquisa bibliográfica, projetos e relatório, publicações e trabalhos científicos. 5. ed. São Paulo: Atlas, 2001.

LIMONGI-FRANÇA, Ana C.; ARELLANO, Eliete B. Os processos de Recrutamento e Seleção. As pessoas na organização, São Paulo: Gente, 2002.

OLIVEIRA, Sílvio Luiz de. Tratado de metodologia científica: projeto de pesquisa, TGI, TCC, monografias, dissertações e teses. São Paulo: Pioneira, 2001.

SILVA, Michelle Souza. Custos e Despesas com Pessoal: um Estudo de Caso na Empresa Móveis Gazin. 2007. Disponível em: http://www.zemoleza.com.br/trabalhoacademico/humanas/contabilidade/custos-e-despesas-com-pessoal-um-estudo-decaso-na-empresa-moveis-gazin/. Acesso em 02/10/2017.

\section{APÊNDICE}

pesquisa interna

Cursando Administração na instituição de ensino UEMG - CLÁUDIO.

Prezado colaborador 
Esta pesquisa busca conhecer sua opinião sobre o serviço de recrutamento e seleção desta empresa voltada para um trabalho de faculdade sobre os Processos de recrutamento e seleção de uma cooperativa.

Contamos com seu auxílio.

1) Sexo

( ) Masculino ( ) Feminino

2) Idade

( ) De zero a 18 anos

( ) De 19 a 23 anos

( ) De 24 a 28 anos

( ) De 29 a 33 anos

( ) De 34 a 38 anos

( ) De 39 a 48 anos

() De 49 a 53 anos

( ) De 54 a 58 anos

( ) 59 anos ou mais

3) Grau de escolaridade

( ) Ensino Fundamental incompleto

( ) Ensino Fundamental completo

( ) $2^{\circ}$ grau incompleto

RC: 20727

Disponível em: https://www.nucleodoconhecimento.com.br/administracao/processo-derecrutamento 
( ) $2^{\circ}$ grau completo

( ) 3o grau incompleto

( ) 3o grau completo

( ) Pós graduação

( ) Mestrado

( ) Doutorado

4) Tempo de serviço na empresa

( ) Menos de um ano

( ) Entre um e cinco anos

( ) Entre cinco e dez anos

() Mais de 10 anos

RECRUTAMENTO E SELEÇÃO

1) Como é a rotatividade de funcionários?

2) O processo de recrutamento e seleção é eficaz?

3) Como é feito o processo de recrutamento e seleção e quais são as técnicas utilizadas?

4) Quais são os critérios do recrutamento e seleção?

5) É feito um planejamento de recrutamento e seleção?

6) É realizada uma avaliação do recrutamento e seleção? 
7) Qual é o absenteísmo?

8) Quais são os motivos que levam a Cooperativa a demitir um funcionário? E quais são os motivos dos funcionários pedirem demissão?

9) Como é feita a entrevista de desligamento?

10) Quais são os custos com o processo seletivo?

11) Quais são os pontos fortes e fracos do processo de recrutamento e seleção da Cooperativa?

Recebido: dezembro de 2017

Aprovado: setembro de 2018 